\title{
Estrutura Conceitual de Plataforma de eGov para o Ministério do Turismo (MTur)
}

\author{
Concept Platform Structure of eGov for the Tourism Ministry (MTur) \\ Estructura Conceptual de Plataforma de eGrov para Ministerio del Turismo (MTur)
}

Alexandre Augusto Biz

Universidade Federal de Santa Catarina (UFSC), Brasil

DOI: https://doi.org/10.18472/cvt.19n3.2019.1483 Redalyc: http://www.redalyc.org/articulo.oa?

bizdetur@gmail.com id $=115461709004$

Roberto Carlos dos Santos Pacheco

Universidade Federal de Santa Catarina (UFSC), Brasil

roberto.pacheco@ufsc.br

José Leomar Todesco

Universidade Federal de Santa Catarina (UFSC), Brasil

jose.todesco@ufsc.br

Recepción: 03 Septiembre 2017

Aprobación: 02 Agosto 2019

\section{Resumo:}

As condições políticas e o ambiente de negócios em turismo são espelho da estrutura de governança pública e de governo aberto (eGov) no Brasil, identificados nos estudos de competitividade do turismo pelo WEF e pelo índice de desenvolvimento de eGov pela United Nations. Buscou-se nesta pesquisa apresentar uma estrutura conceitual de plataforma de eGov para o Ministério do Turismo. Pesquisa exploratória de abordagem qualitativa, conceitualmente estruturado em Kalbaska et al. (2016) com conjunto de relacionamentos entre atores via plataforma eGov, em Biz (2014) com elementos e os fatores associados à gestão do conhecimento no setor turístico, em Thomas et al. (2014) com visão dos múltiplos subsistemas associados a plataformas de informação e Pacheco et al. (2015) com a e-governança. Entre os resultados potenciais da aplicação da plataforma proposta estão o apoio intensivo de tecnologias na ampliação de valor agregado dos serviços e bens turísticos, na formação atual e futura de pessoas para atuar no setor, na formalização de MEI e ME, e na busca constante de inovação.

Palavras-Chave: Turismo, Plataforma de Negócios, Governo Eletrônico.

\section{Abstract:}

Political conditions and business environment in tourism are a mirror of the structure of public governance and e-government (eGov) in Brazil, identified in the tourism competitiveness studies by the WEF and the eGov development index by the United Nations. This research aimed to present a conceptual framework of eGov platform for the Ministry of Tourism. Exploratory research of qualitative approach conceptually structured in Kalbaska et. al (2016) with a set of relantionships bettween actors by platform of eGov, Biz (2014) with modeling knowledge management architecture, Thomas et al. (2014) on the concepts of platform ecosystems, and Pacheco et al. (2015) as its e-governance. The main result is stimulating value-added tourism products and services, present and future of people training, formalization of MEI and ME, and the search for innovation. Consecutively, benefit the companies involved directly or complementary on the platform to expand their market performance.

KEYWORDS: Tourism, Business Platform, Electronic Government.

\section{RESUMEN:}

Las condiciones poli ticas y el ambiente de negocios en turismo son un espejo de la estructura de la gobernanza pu blica y del gobierno electrónico (eGov) en Brasil. Identificados en los estudios de competitividad del turismo por WEFy por el indice de desarrollo de e Gov por la United Nations. El estudio presenta una estructura conceptual de plataforma de eGov para el Ministerio del Turismo. Investigación exploratoria de enfoque cualitativo, conceptualmente estructurada en Kalbaska et al. (2016) con las relaciones entre los actores de la plataforma de eGov, Biz (2014) con elementos y los factores asociados a la gestión del conocimiento en el sector turisticos, Thomas et. al. (2014) en los conceptos de ecosistemas de plataforma, y por Pacheco et. al (2015) cuanto su e-gobernanza. El principal resultado está en estimular valor agregado en los productos y servicios turisticos, la formación actual y futura de personas, la formalización de MEI 
y ME, y en la búsqueda de innovación. Consecutivamente, beneficiar las empresas involucradas directamente o complementares en la plataforma para ampliar sus mercados de actuación.

Palabras Clave: Turismo, Plataforma de Negocios, Gobierno Electrónico.

\section{INTRODUÇÃO}

Para World Travel \& Tourism Council(WTTC) (2018) as receitas turísticas do Brasil no ano de 2017 foram compostas em $94,3 \%$ por gastos de visitantes domésticos e $7,7 \%$ por gastos de visitantes estrangeiros. Essas receitas analisadas como impactos diretos, indiretos e induzidos no turismo geraram USD 219,8 bilhões, representando $7,9 \%$ do produto interno bruto - PIB, brasileiro, abrangendo aproximadamente 7 milhões de empregos (i.e, 7,8\% dos empregos gerados no País).

Outros importantes indicadores sobre o turismo no Brasil são apresentados pelo World Economic Forum (WEF) (2017). No estudo sobre competitividade em viagens e turismo que avaliou 141 países, a Espanha foi definida como o destino turístico mais competitivo, enquanto o Brasil ficou em $27^{\circ}$ no ranking mundial e em primeiro na América do Sul. Avaliando os índices de competitividade, os melhores foram: primeiro em relação a "recursos naturais" e oitavo em "recursos culturais e viagens de negócios". Não obstante, como piores índices, ocupou a $106^{a}$ posição em "prioridade em viagens e turismo" e a 126 a posição em "ambiente de negócios".

Em relação aos sub índices analisados do indicador "prioridade em viagens e turismo", o "papel do Estado na definição da prioridade" ficou em $126^{\circ}$, as "despesas do Governo" em $79^{\circ}$, a "efetividade do marketing promocional" em $121^{\circ}$, "abrangência de dados" em $104^{\circ}$, "disponibilidade temporal dos dados" em $93^{\circ}$ e a "estratégia de marca" em $14^{\circ}$. Já dentre os sub índices de "ambiente de negócios", destacam-se "efeitos da tributação sobre os incentivos para investir e empregar" que ficou em $136^{\circ}$, "tempo para abertura do negócio" em $133^{\circ}$, "eficiência de resolução de litígios de enquadramento legal" em $106^{\circ}$.

As condições políticas e o ambiente de negócios em turismo são semelhantes na estrutura de governança pública e do governo eletrônico (eGov) no Brasil. Na pesquisa da United Nations (2014) o País ficou classificado na $57^{\text {a }}$ posição quanto ao índice de desenvolvimento de governo eletrônico que avaliou 190 países. Os objetivos de eGov propostos pela United Nations (2014) são serviços de maior qualidade com menos recursos, mais inclusiva e maior capacidade holística dos governos; mais aberta, transparente, responsável e eficaz na gestão pública; e que responda à crescente demanda cidadã e, respectivamente, a uma maior participação na construção da confiabilidade de um governo.

Neste sentido, a Espanha vem se destacando ao criar normas que objetivam ampliar sua vantagem competitiva a citar, como exemplo, a norma UNE 178301 de 2015 que define critérios para eGov (dados abertos) para cidades inteligentes, a norma UNE 178303 de 2015 sobre especificações de gestão de cidades inteligentes e, por fim, a norma UNE 178501 de 2016 com requisitos para gestão de destinos turísticos inteligentes, sendo que todas estas normas estão inter-relacionadas (AENOR, 2015a, 2015b, 2016).

Corroborando com as discussões na Espanha, os pesquisadores Moreno, Hörhager, Schuster e Werthner (2015) observaram o turismo como plataforma de serviços abertos, de cooperação e de inovação estratégica entre os envolvidos.

A partir deste cenário, buscou-se nesta pesquisa apresentar estrutura conceitual de plataforma de eGov para o Ministério do Turismo, sendo este definido como agente líder de uma plataforma de negócios em turismo que visa o processo de criação de valor e de inovação em produtos e serviços turísticos entre todos os envolvidos na mesma. 


\section{A GOVERNANÇA PÚBLICA E GOVERNO ELETRÔNICO (EGov)}

A governança pública trata do desempenho das organizações governamentais e do seu impacto no desenvolvimento da sociedade. Por esta razão, existem diferentes definições e abordagens para a temática. Para United Nations (2007), a governança pública se refere a combinações formais e informais que determinam como são tomadas as decisões públicas e como são realizadas as ações públicas com a finalidade de preservar os valores da sociedade a que se refere.

Ao mesmo tempo, a governança pública tem como objetivo um conjunto de ideais, práticas e instrumentos de gestão das organizações governamentais, a prestação de contas à sociedade e a gestão dos recursos econômicos e sociais de um país (OECD , 2005; WORLD BANK, 2013).

$\mathrm{Na}$ prática, para os gestores públicos governança implica em preocupações quanto à busca pela efetividade no cumprimento da sua missão organizacional e pelo exercício dos valores como participação, transparência e coprodução com a sociedade.

Ronconi (2011) cita que a governança pública, enquanto gestão governamental, pressupõe o desejo político de implementação de um projeto democrático que possibilite maior articulação entre o Estado e a sociedade civil, a construção de espaços públicos e da ampliação da política, na medida em que considera a importância da sociedade civil na decisão e formulação de políticas públicas.

Rampelotto, Löbler e Visentini (2015, p. 960-961) citam que:

o gestor público tem o papel de identificar as oportunidades oriundas da utilização das TICs e do e-Gov, inovando, racionalizando processos e adotando modelos de gestão que priorizem a disponibilização de informaçóes e serviços para os cidadãos por meio da internet, ao mesmo tempo que a administração pública se abre para a participação e o controle social, estimulando o exercício pleno da cidadania.

Salm Junior (2012) destacou tendências recentes nos modelos de governança pública, com a eminente necessidade de transformações nos projetos de governo eletrônico (eGov), justamente devido a essa expectativa do crescimento da participação dos cidadãos na evolução eletrônica das ações do governo para estabelecer fortes reações políticas entre eles.

Essa visão do governo eletrônico como instrumento de transformação na relação governos-sociedade é intrínseca à visão de conexão entre eGov e governança pública. A Organização para a Cooperação e Desenvolvimento Econômico (OCDE) (OECD, 2003) definiu eGov como o uso das tecnologias de informação e comunicação como ferramentas para alcançar uma melhor governança.

Dawes (2009, apud LARSSON e GRÖNLUND, 2014) apresenta seis áreas vitais para o eGov, $1^{a}$ ) propósito e função do governo, $2^{a}$ ) as tendências sociais, $3^{a}$ ) os elementos das interações humanas, $4^{a}$ ) a complexidade, $5^{a}$ ) as mudanças das tecnologias e a $6^{a}$ ) gestão da informação.

Pacheco, Sell, Salm Júnior e Todesco (2015) ressaltam o plano da visão política da OCDE, que descreve a importância do governo exercer liderança nos projetos de eGov, pois somente assim haverá uma visão de longo prazo e o comprometimento efetivo com a melhoria dos processos e serviços, ou seja, que prevaleça a visão de Estado sobre as necessidades momentâneas do governo.

Pacheco et. al. (2015) apresentam os princípios da governança pública como aspectos de performance, controle social e capital social. A performance da governança pública está relacionada ao desempenho quanto à eficiência e eficácia dos serviços prestados aos cidadãos, e o controle social se refere à prestação das suas contas para com a sociedade e aos órgãos responsáveis pela fiscalização, assim como a transparência das ações e gastos públicos dos recursos da sociedade. Já o capital social é a participação e coprodução da sociedade nas decisões políticas, estratégias e ações (PACHECO et. al., 2015).

Segundo a European Commission (EC) (2016) eGov é mais do que prover tecnologia. A administração moderna deve não somente prestar serviços públicos para os cidadãos e empresas, como ser referência para relações contemporâneas entre cidadãos e empresas. Em seu plano de ação de eGov 2016-2020 a EC (2016) 
buscou modernizar a administração pública, levar a cabo o mercado interno digital e se comprometer mais com os cidadãos e as empresas para oferecer serviços de alta qualidade.

Para Moutet (2012) os serviços de eGov devem atender distintos setores, tais como empresas, cidadãos, associações, autoridades locais e governo central. $\mathrm{O}$ autor assinala que uma das maneiras de entrega e compartilhamento desses serviços está em uma plataforma de modelo de negócios.

Rana, Dwivedi \& Williams (2013) realizaram uma investigação exaustiva em 78 artigos de um conjunto de 448 sobre eGov. O resultado mostrou que a maioria dos artigos apontavam os objetivos entre a relação da oferta e demanda, barreiras e fatores críticos de êxito.

Especificamente sobre os fatores críticos de êxito, Rana et al. (2013) identificaram em sua pesquisa a satisfação do usuário (utilidade e precisão das informações), proteção e segurança jurídica, a infraestrutura do website, capacitação dos prestadores de serviços para melhor atendimento às demandas e a gestão da informação.

Rana et al. (2013) concluíram que essa síntese pode funcionar como um guia para os governos para ações preventivas evitando as barreiras e os riscos no processo de implementação de uma iniciativa de eGov.

Finalmente, Tambouris, Kaliva, Liaros e Tarabanis (2014) destacam que um dos principais objetivos do eGov é a prestação de serviços públicos online, entretanto, muitos dos sistemas de eGov falham na incapacidade de alcançar os objetivos pré-definidos, do planejamento e desenho do projeto deste tipo e sobre tudo os problemas de arquitetura da plataforma de eGov (brecha entre a realidade e o desenho).

Wimmer (2002) reforça que uma plataforma de eGov deverá permitir ao setor público oferecer aos cidadãos, à s empresas e ao apoio pessoal administrativo do setor público, a informação baseada em acontecimentos em tempo real e as situações de negócios, conseguindo o aumento da eficácia, eficiência e qualidade dos serviços públicos.

\section{EGov E DADOS ABERTOS NO TURISMO}

Uma das formas de efetivar a infraestrutura de dados necessária para viabilizar a visão de eGov contemporâneo, visto como fator de promoção da governança pública moderna, está na criação de repositórios de dados abertos ou, como referenciado na literatura, na promoção do governo aberto.

A norma UNE 178501/2016 (AENOR, 2016) com requisitos para gestão de destinos turísticos inteligentes na Espanha é um exemplo de eGov contemporâneo, que define como requisitos mínimos para os gestores a gestão aberta e participativa (interação cidadão, gestor público, turista), a gestão transversal e coerente (integração com outros setores públicos), gestão transparente (comunicação acessível a todos) e gestão responsável e controlada (eficácia na política e eficiência nos recursos).

No Brasil, cita-se um movimento pontual deste processo, com a publicação em julho de 2016 do Plano de Dados Aberto (PDA) do Ministério do Turismo (MTur), um documento orientador para "as ações de implementação e promoção de abertura de dados no Ministério do Turismo (MTur), obedecendo a padrões mínimos de qualidade, de forma a facilitar o entendimento e a reutilização das informações" (BRASIL, 2016b, p.7).

O PDA está fundamentado no Decreto Presidencial n 6.666, de novembro de 2008 - Infraestrutura Nacional de Dados Especiais, na Lei de Acesso à Informação (LAI) - Instrução Normativa da Secretaria de Logística e Tecnologia da Informação (SLTI), nº 4, de 13 de abril de 2012, no Decreto ${ }^{\circ}$ 8.777, de 11 de maio de 2016 - Política de Dados Abertos do Poder Executivo Federal, e nos compromissos assumidos pelo País no âmbito do $2^{\circ}$ Plano de Ação Nacional sobre Governo Aberto, entre outros normativos (BRASIL, 2016a).

No Brasil, para o setor de Turismo - objeto da pesquisa deste trabalho - o projeto mais próximo dessas premissas está na proposta do Plano de Dados Abertos do MTur (BRASIL, 2016b, p. 11), que tem como objetivo 
Promover a abertura de dados no Ministério do Turismo, zelando pelos princípios da publicidade, transparência e eficiência, visando ao aumento da disseminação de dados e informações para a sociedade, bem como a melhoria da qualidade dos dados disponibilizados, a fim de dar maior suporte à tomada de decisão pelos gestores públicos e ao controle social.

O Ministério do Turismo (BRASIL, 2016b) ressalta que esta abertura deve garantir os princípios da publicidade e transparência da administração pública, levando-se em consideração o grau de relevância para o cidadão, os normativos legais e os compromissos formalmente assumidos pelo MTur e alinhamentos com planejamento estratégico institucional.

Governança, eGov e dados (governo) abertos podem ser melhor viabilizados se houver um projeto integrador para as diferentes tecnologias da informação que oferecem acesso aos serviços públicos. Uma das formas de prover esse instrumento é por meio de plataformas eGov sistêmicas.

\section{PLATAFORMAS DE NEGÓCIOS E EGov}

O conceito sobre plataforma é utilizado para descobrir fenômenos de gestão no nível de produção individual, sistemas de produtos, cadeia de fornecedores, mercados, empresas próximas e outras (GAWER, 2009, apud THOMAS, AUTIO e GANN, 2014).

Sawney (1998, apud GAWER, 2010) sugere que as empresas devem mudar de portfólio de coisas para plataforma de portfólio, onde se objetiva compreender os eixos comuns que unem as empresas quanto às ofertas, mercados, processos, e explorar esses pontos em comum para desenvolver crescimento e variedade de produtos e serviços. (grifo nosso)

Gawer (2010) apresenta quatro tipos de plataformas, i) a interna - dentro de uma empresa, ii) cadeia de fornecedores - entre os fornecedores, iii) empresas - ecossistemas de empresas, e iv) mercado múltiplo diferentes empresas e mercados.

Independentemente da definição da corrente teórica sobre a plataforma, Gawer (2011) apresenta uma estratégia para transformá-la em plataforma líder:

\# Opção estratégica: criar uma plataforma sem precedentes;

\# Ações tecnológicas que considerar: solucionar essencialmente o problema de sistema, facilitar às empresas externar e providenciar outras solicitações, manter a propriedade intelectual fechada no interior da sua tecnologia, manter forte interdependência entre a plataforma e complementos;

\# Ações de negócios que considerar: resolver essencialmente o problema de negócios para as diversas empresas participantes, criar e preservar incentivos para as empresas complementares com a finalidade de contribuir e inovar, proteger sua principal fonte de recursos e benefícios, manter a competitividade (alto custo para mudança de plataforma por empresas).

Na pesquisa de Thomas, Autio y Gann (2014) sobre o uso da expressão “plataforma” em 183 artigos científicos, estruturaram em correntes teóricas fundamentadas em plataforma organizacional, família de produto, mercado intermediário e plataforma de ecossistemas, conforme o quadro 1. 
QUADRO 1

Correntes Teóricas de Plataforma

\begin{tabular}{|c|c|c|c|c|}
\hline \multirow{2}{*}{$\begin{array}{l}\text { Base da } \\
\text { Corrente }\end{array}$} & \multicolumn{4}{|l|}{ Modelo } \\
\hline & Organizacional & $\begin{array}{l}\text { Família de } \\
\text { Produto }\end{array}$ & $\begin{array}{l}\text { Mercado } \\
\text { Intermediário }\end{array}$ & $\begin{array}{l}\text { Ecossistemas de } \\
\text { Plataforma }\end{array}$ \\
\hline Variantes & $\begin{array}{l}\text { Plataforma de } \\
\text { investimento, } \\
\text { plataforma } \\
\text { tecnológica }\end{array}$ & $\begin{array}{l}\text { Plataforma } \\
\text { interna, } \\
\text { plataforma de } \\
\text { cadeia de } \\
\text { intermediários }\end{array}$ & $\begin{array}{l}\text { Múltipla } \\
\text { plataforma, } \\
\text { plataforma } \\
\text { dos lados }\end{array}$ & $\begin{array}{l}\text { Plataforma } \\
\text { empresarial, } \\
\text { plataforma } \\
\text { tecnológica }\end{array}$ \\
\hline Construção & $\begin{array}{l}\text { Capacidade } \\
\text { dinâmica }\end{array}$ & $\begin{array}{l}\text { Família de } \\
\text { produtos }\end{array}$ & $\begin{array}{l}\text { Mercado } \\
\text { múltiplo }\end{array}$ & $\begin{array}{l}\text { Ecossistema de } \\
\text { plataforma }\end{array}$ \\
\hline $\begin{array}{l}\text { Descrição } \\
\text { como } \\
\text { plataforma }\end{array}$ & $\begin{array}{l}\text { Capacidade } \\
\text { organizacional } \\
\text { para permitir } \\
\text { performance }\end{array}$ & $\begin{array}{l}\text { Centro estável } \\
\text { de plataforma } \\
\text { de família líder } \\
\text { de produtos }\end{array}$ & $\begin{array}{l}\text { Provedor } \\
\text { entre duas } \\
\text { ou mais } \\
\text { participantes } \\
\text { do mercado }\end{array}$ & $\begin{array}{l}\text { Sistema da } \\
\text { arquitetura que } \\
\text { Suporta um } \\
\text { conjunto de } \\
\text { ativos } \\
\text { complementares }\end{array}$ \\
\hline $\begin{array}{l}\text { Nível de } \\
\text { análises }\end{array}$ & Empresa & Produto & Empresa & Sistema/Empresa \\
\hline $\begin{array}{l}\text { Núcleo da } \\
\text { assinatura }\end{array}$ & Estratégia & $\begin{array}{l}\text { Desenvolvimento } \\
\text { de Produto }\end{array}$ & $\begin{array}{l}\text { Economia } \\
\text { empresarial }\end{array}$ & $\begin{array}{l}\text { Estratégia } \\
\text { tecnológica }\end{array}$ \\
\hline $\begin{array}{l}\text { Conceitos } \\
\text { chave }\end{array}$ & $\begin{array}{l}\text { Núcleo de } \\
\text { capacidade; } \\
\text { opçôes reais; } \\
\text { capacidades } \\
\text { dinâmicas } \\
\end{array}$ & $\begin{array}{l}\text { Família de } \\
\text { produtos; } \\
\text { arquitetura; } \\
\text { modularidade }\end{array}$ & $\begin{array}{l}\text { Externalidade } \\
\text { de relações; } \\
\text { padrōes; } \\
\text { mercado } \\
\text { multi facetas }\end{array}$ & $\begin{array}{l}\text { Externalidade de } \\
\text { relações; } \\
\text { inovações; } \\
\text { padrôes; } \\
\text { modularidade }\end{array}$ \\
\hline $\begin{array}{l}\text { Criação de } \\
\text { valor }\end{array}$ & $\begin{array}{l}\text { Flexibilidade; } \\
\text { adaptação } \\
\text { Superior }\end{array}$ & $\begin{array}{l}\text { Flexibilidade; } \\
\text { redução dos } \\
\text { custos; inovação }\end{array}$ & $\begin{array}{l}\text { Eficiência de } \\
\text { mercado; } \\
\text { estrutura de } \\
\text { preço; poder } \\
\text { de mercado }\end{array}$ & $\begin{array}{l}\text { Flexibilidade, } \\
\text { redução dos } \\
\text { custos; inovação, } \\
\text { externalidades; } \\
\text { aprendizagem; } \\
\text { poder de } \\
\text { mercado }\end{array}$ \\
\hline $\begin{array}{l}\text { Apropriação } \\
\text { de valor }\end{array}$ & Não tem & $\begin{array}{l}\text { Propriedade; } \\
\text { Controle } \\
\text { arquitetônico }\end{array}$ & $\begin{array}{l}\text { Propriedade; } \\
\text { Mecanismos } \\
\text { institucionais }\end{array}$ & $\begin{array}{l}\text { Controle } \\
\text { arquitetônico; } \\
\text { propriedade de } \\
\text { elementos } \\
\text { críticos e } \\
\text { legitimidade }\end{array}$ \\
\hline
\end{tabular}

Fonte: Adaptado Thomas, Aution e Gann (2014)

Percebe-se no quadro 1 que o modelo de ecossistemas de plataforma é mais abrangente do que os demais, pois sua arquitetura está dimensionada para a participação de diversos atores e seu conceito chave está na externalidade de relações, nas inovações, nos padrões e nas modularidades. Pode-se afirmar que esse modelo de ecossistema de plataforma representa a dimensão do turismo que é transversal (necessidade de multirrelações) e contínuo em inovações (tecnológicas, processos, serviços, marketing e gestão).

Os participantes destes ecossistemas seguem uma estrutura na qual o líder da plataforma atua como membro chave (eixo central) da rede de empresas que são complementos da mesma plataforma. Ao mesmo tempo que também como um conjunto de interdependência tecnológica e estratégica entre o núcleo da plataforma. Essas empresas complementares ocupam uma posição periférica na rede (GAWER, 2010).

Moreno et al. (2015) descrevem que os destinos turísticos cumprem os pré-requisitos de uma plataforma de ecossistema, pois apresentam um ecossistema regional e nacional de usuários, prestadores de serviços, serviços e produtos complementares, entre outros. Ressaltam que os gestores dos destinos turísticos podem usar como estratégia de plataforma, i) criar uma massa crítica e aumentar as suas possibilidades de distribuição, ii) facilitar o processo de inovação tecnológica devido à visão da plataforma como “open service" e iii) promover 
a cooperação das organizações de turismo com outros ramos de atividade. Possibilitando desta forma, uma vantagem competitiva sobre os destinos turísticos a partir das inovações.

Para Cusumano (2010, apud MORENO et al.2015) a plataforma deve oferecer tecnologias e serviços para uma gama de ecossistemas de empresas e de usuários. Para as empresas, ligadas direta e indiretamente ao setor turístico (públicas, privadas ou mista), a plataforma deve permitir a troca de dados e informações e integrações tecnológicas. Os usuários, por sua vez, não acessam diretamente à plataforma, mas sim à s aplicações das empresas que atuam na plataforma. Portanto, a plataforma funciona como espinha dorsal para a criação de novos serviços e produtos turísticos.

Em relação ao que se espera de plataformas de negócio, é justamente essa falha no atendimento dos serviços o primeiro ponto de insucesso do eGov como instrumento-referência na governança. Na seção a seguir, verificam-se esses pontos especificamente no caso da proposta do Ministério do Turismo.

\section{A ESTRUTURA CONCEITUAL DA PLATAFORMA DE eGov PARA O MiNISTÉRIOS DO TURISMO}

Nas seções anteriores verificamos como a literatura tem articulado os conceitos de governança, eGov e plataformas de negócio em eGov. Nesta seção, verifica-se, a partir desse referencial, de que forma eGov tem sido empregado no setor de turismo e, mais especificamente, como seria possível propor uma estrutura conceitual de plataforma eGov com potencial de promover negócios de interesse público neste setor.

Para tal, utilizou-se na pesquisa o método exploratório qualitativo que objetiva prover os investigadores de um maior conhecimento sobre a temática e/ou do problema de pesquisa (ANDRADE, 2003; MATTAR, 1996). Buscou-se pela pesquisa de conceitos, modelos e metodologias sobre plataforma de negócios e eGov em artigos científicos por meio do Portal de Periódicos CAPES, sistema Science Direct e Taylor \& Francis, e teses e dissertações de nas áreas da Administração, Contabilidade e Turismo, Engenharias III (foco na Engenharia de Produção) e Interdisciplinar (foco Engenharia e Gestão do Conhecimento).

Referente aos conteúdos "eGov e Turismo", "eGov and Tourism", "plataforma de negócios em turismo" e "Business Platform in Tourism" foram realizadas pesquisas nos artigos dos livros Information and Communication Technologies in Tourism de 2006 a 2016 de gestão da International Federation for IT and Travel \& Tourism (IFITT), e em teses e dissertações dos Programas de Pós-Graduação associados à Associação Nacional de Pesquisa e Pós-Graduação (ANPTUR)

Como resultado, não foram identificadas teses ou dissertações ligadas aos programas associados à ANPTUR contemplando os conteúdos temáticos apresentados, bem como em artigos científicos nacionais e internacionais. Entretanto, três capítulos dos livros da IFITT foram selecionados, sendo dois capítulos com correlação parcial ao conteúdo: o primeiro, de autoria de Michopoulou e Buhalis (2006), denominase "Developing an eTourism Platform for Accessible Tourism in Europe: Technical Challenges" e tem foco na acessibilidade visual, no design e nas informações (não tratando da construção da arquitetura da plataforma); e o segundo, de autoria de Bilbao, Lejarazu e Herrero (2010), denomina-se "Dynamic Packaging Semantic Platform for Tourism Intermediaries" e objetiva a construção de uma arquitetura de informações a partir da identificação semântica de uma solicitação de um consumidor.

Além desses, há o trabalho (capítulo do livro) de autoria de Kalbaska, Janowski, Estevez e Cantoni (2016), com título "E-Government Relationships Framework in the Tourism Domain. A First Map". Essa pesquisa traz mais assertividade ao objeto deste estudo, pois tratou de diferentes camadas da política e da governança do turismo. $\mathrm{O}$ trabalho explorou domínio de aplicações existentes em eGov e evidenciou as múltiplas relações entre stakeholders - Governo-Governo (G2G), Governo-Negócios (G2B), GovernoCidadão (G2C), Governo-Terceiro Setor (G2N), Governo-Empregados (G2E) e Governo-Visitante (G2V) - o que vai ao encontro da proposta da presente pesquisa. 
Kalbaska et al. (2016) ressaltam como oportunidades de pesquisas futuras analisar como tais relações são executadas, como aumentar ou diminuir o desempenho do setor ou organização em diferentes contextos nacionais e institucionais, e sugerem a pesquisa adicional sobre de que diferentes formas TIC podem melhorar o desempenho e impacto de tais mecanismos.

Desse modo, esta pesquisa tem, em seus resultados, a combinação multifacetada de conceitos. Em relação às diferentes relações entre atores associados ao setor turístico, o trabalho de referência é a pesquisa recente publicada por Kalbaska et al. (2016). Para a concepção sistêmica dos diferentes elementos que devem estar presentes quando se considera a gestão do conhecimento como um dos instrumentos de posicionamento exitoso do eGov, tem-se como referência o trabalho de Biz (2014) com a modelagem de arquitetura de gestão de conhecimento, nos conceitos de ecossistemas de plataforma apresentado por Thomas et al. (2014).

Em relação à eficácia (i.e., resultados perceptíveis na sociedade), inclui-se também as áreas vitais de Dawes (2009, apud LARSSON e GRÖNLUND, 2014) quanto ao propósito e função do governo, as tendências sociais, os elementos das interações humanas, a complexidade, as mudanças das tecnologias e a gestão da informação

Desse modo, verifica-se que as potencialidades dos macroambientes de negócios em turismo não devem ser vistas de forma individual (input: insumo), mas sim devem prever a integração entre os macroambientes para permitir a formação de produtos e serviços turísticos que agregam valor competitivo para o destino turístico, para os stakeholders e cidadãos (output: resultados dos negócios).

Como consequência, uma plataforma de negócios para o turismo deverá estar estruturado em seis pilares, sendo eles: $1^{\circ}$ ) a competência (determinar os papéis dos autores envolvidos e objetivando sempre a promover a inovação), $2^{\circ}$ ) a integração e comunicação entre os participantes (interfaces colaborativas), $3^{\circ}$ ) relacionamento com outros participantes externos ao turismo (grau de cooperação, colaboração, coprodução e criação de produtos e serviços turísticos), $4^{\circ}$ ) a gestão interna da plataforma (participantes alinhados nas mesmas estratégias), $5^{\circ}$ ) participação na internet (gestão dos conteúdos para transformar em conhecimento), e $6^{\circ}$ ) arquitetura (dados, sistema de informação, engenharia do conhecimento).

A premissa da plataforma é a visão "um-para-muitos", a capacidade de maximizar a participação dos diferentes atores da cadeia produtiva (direta e indireta) do turismo para a formação de produtos e serviços turísticos com alto valor agregado, conforme Figura 1. 


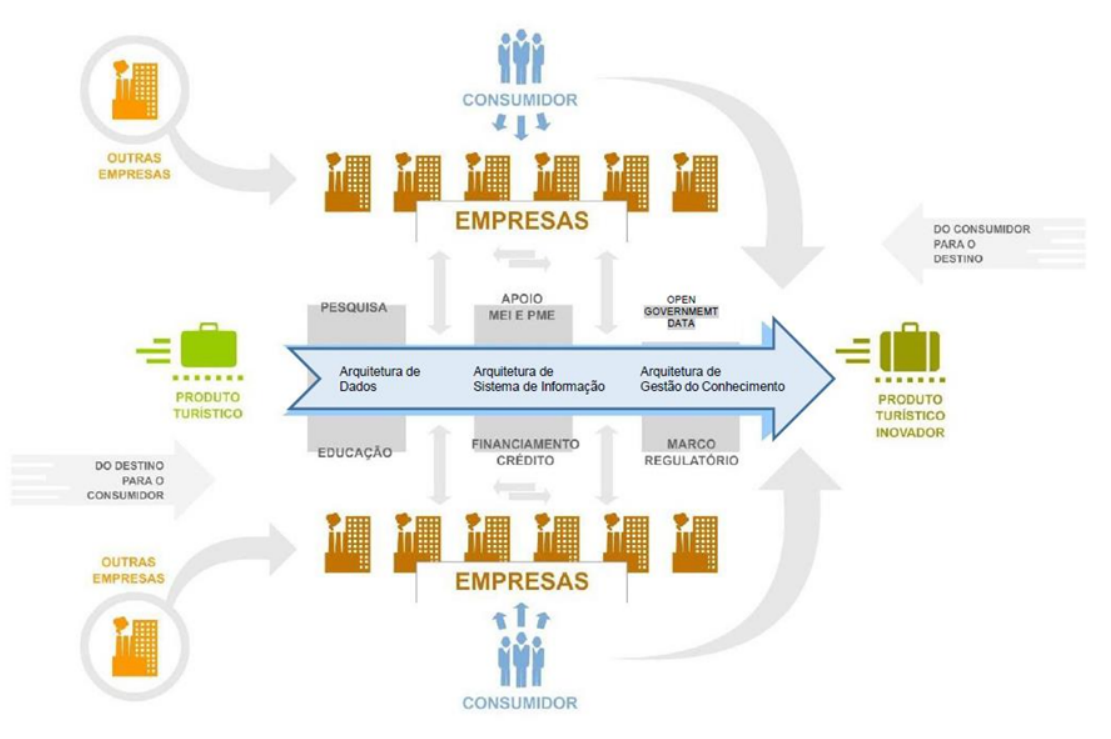

FIGURA 1

Estrutura Conceitual de Plataforma eGov para MTur

Fonte: Adaptado de Biz (2014, apud, Todesco et al, 2014, p. 88)

Ao se criar uma rede de ecossistemas de empresas na plataforma, estas empresas se conectam com outros stakeholders provendo com insumos (know-how), sabedoria e ferramentas para que todos possam contribuir e interagir na formação de produtos e serviços turísticos inovadores, diferenciais e experienciais, auxiliando na criação de novos mercados de consumidores.

Tambouris et al. (2014) sugerem que, para o desenvolvimento da arquitetura, seja utilizado o método de desenvolvimento da arquitetura - ADM de TOGAF, que é um grupo aberto de contribuições contínuas a partir de um grande número de profissionais da arquitetura.

O modelo ADM consta de nove etapas realizadas em um ciclo de maneira que se conecta a tarefa central de requisitos de gestão, sendo i) com as demais, ii) visão da arquitetura, iii) arquitetura de negócios, iv) arquitetura de sistemas de informações, v) arquitetura tecnológica, vi) oportunidades e soluções, vii) planejamento de migração, viii) implementação de governança e, ix) gestão de mudança da arquitetura.

Para Pacheco et al. (2015), no entanto, mecanismos de coprodução como ADM não devem prescindir da visão de governança pública, mantendo representação de todos os stakeholders, com o cuidado da comunicação e a interação não incluir apenas a visão tecnológica. Segundo os autores, cabe à organização pública líder no setor-alvo da plataforma eGov a responsabilidade de manter mecanismos multiinstitucionais de governança e participação, em estreita colaboração com outras unidades governamentais protagonistas no setor.

Assim, no caso do setor do turismo, o papel que o Ministério do Turismo e as demais estruturas do Governo Federal exercem é central para o desenvolvimento da plataforma proposta. Em estreito sistema de coprodução multi-institucional, devem ser definidas as formas de integração de serviços nas dimensões de:

\# Pesquisa: definição de políticas para a pesquisa, desenvolvimento e inovação com incentivos fiscais e financiamento por meio das agências de fomento do Governo Federal e Fundaçóes de Amparo à Pesquisa dos estados;

\# Educação: formação básica para a qualificação profissional em diferentes áreas, como as ofertadas pelo PRONATEC $^{[1]}$, e para desenvolvimento de pesquisa, inovação e desenvolvimento pelas Instituições de Ensino Superior, Instituição Científica e Tecnológica (ICT), Organizações Sociais, entre outras; 
\# Apoio ao Microempreendedor Individual (MEI) e Microempresa (ME): políticas para o desenvolvimento destas empresas no setor turístico, burocracia (abertura e fechamento), linhas de créditos e financiamento (infraestrutura para inovação), planejamento/assistência (orientação);

\# Financiamento e Crédito: políticas dos bancos de desenvolvimento do Governo Federal, Regionais e Estatais para a concessão de financiamento e crédito para projetos de desenvolvimento turístico ou outras áreas que impactam indiretamente no turismo;

\# Marco legal: definição de políticas públicas para o turismo com leis, decretos, outros que possibilitem aos participantes segurança jurídica;

\# Open Government Data: transparência, compartilhamento e reutilização de dados, informação e conhecimento, impulsionar a criação de empresas e serviços que aportem valor social e comercial inovadores, baseado no modelo European eGovernment Action Plan 2016-2020, e em atendimento ao Plano de Dados Abertos do Ministério do Turismo (BRASIL, 2016b).

\# Arquitetura tecnológica: projeto e desenvolvimento eGov que cria, disponibiliza e recebe dados turísticos, em consonância com o modelo de governo aberto, bem como estabelece espaços de coprodução com organizações governamentais, empresas e com a sociedade civil organizada.

Em sua maioria, os serviços listados referem-se às funções estratégicas à plataforma de negócios do turismo, que vai da pesquisa à definição de marcos legais. Os dois últimos referem-se a serviços socio tecnológicos que trazem bases conceituais e tecnológicas para a arquitetura eGov e para a governança pública em Turismo. Quando virtuosos, esses serviços culminam na interação e na integração entre empresas da rede (tanto privadas como públicas) e consumidores, via tecnologia da informação e comunicação (telefonia móvel, APP, www, redes sociais, outros), tornando os consumidores como agentes de cocriação, coprodução e copromoção dos produtos e serviços turísticos.

\section{CONSIDERAÇÕES FINAIS}

A priori, o Decreto no 8.638 de 15 de janeiro de 2016, que instituiu a Política de Governança Digital no âmbito dos órgãos e das entidades da administração pública federal direta, autárquica e fundacional, foi um grande avanço para o País e para atividade turística, ao citar em seu artigo $1^{\circ}$ nos incisos " $I$ - gerar benefícios para a sociedade mediante o uso da informação e dos recursos de tecnologia da informação e comunicação na prestação de serviços públicos; II - estimular a participação da sociedade na formulação, na implementação, no monitoramento e na avaliação das políticas públicas e dos serviços públicos disponibilizados em meio digital; e III - assegurar a obtenção de informações pela sociedade, observadas as restriçóes legalmente previstas."

Observa-se que o Decreto citado vem ao encontro d o plano de ação de eGov 2016-2020 da EC que, teoricamente, deveria modernizar a administração pública, ampliar a digitalização dos serviços e principalmente, oferecer aos cidadãos e às empresas serviços de qualidade.

O modelo conceitual proposto nesta pesquisa como plataforma eGov voltada ao turismo, percebido como setor de protagonismo multi-institucional de entidades governamentais, empresas (públicas e privadas), academia e sociedade civil organizada, tem como objetivo estimular e ampliar o valor agregado de bens e serviços turísticos, a formação atual e futura de pessoas para atuar no setor, a formalização de MEI e ME, e a busca pela inovação, beneficiando todos os atores envolvidos de forma direta ou complementar na cadeia de valor do turismo.

A criação uma rede de ecossistemas de empresas na plataforma que se conectam com outros stakeholders provendo com insumos (know-how), sabedoria e ferramentas para que todos possam contribuir e interagir na formação de produtos e serviços turísticos inovadores, diferenciais e experienciais, auxiliando na criação de novos mercados de consumidores. 
Também se considera a multi-institucionalidade de cada ator, como no caso das empresas que não se limitam ao comércio entre elas, mas no intercâmbio de serviços e bens, assim como tecnologias, fazem parte direta ou indiretamente da cadeia produtiva do turismo.

Apesar de ser ainda uma proposta empírica, a estrutura da plataforma de negócios foi utilizada por Pavan (2016) em uma pesquisa realizada em Curitiba, Região e Litoral Convention \& Visitors Bureau $(\mathrm{CCVB})^{[2]}$, que teve como objetivo de analisar o fluxo de informação e o processo de criação do conhecimento organizacional. Entre os resultados alcançados estava o apoio aos processos de criação e compartilhamento do conhecimento, às rotinas e aos processos diários da organização, à melhoria da comunicação interna $\mathrm{e}$ entre as empresas envolvidas, ao compartilhamento das melhores práticas, à melhoria do desempenho e da assertividade das ações dos gestores do CCVB na tomada de decisões (PAVAN, 2016).

Por fim, percebeu-se nas discussões teóricas que apenas a publicação de Leis, Decretos, Normas e outros instrumentos legais não garantem as suas respectivas implementações, requer uma execução de um projeto integrador e uma visão de Estado. Destaca-se que até a publicação deste artigo, não há relato de um projeto integrador constituído pelo gestor principal o Ministério do Turismo; fundos de amparo à pesquisa - CNPq, CAPES, FINEP; centros de excelência em pesquisa e desenvolvimento, como as Universidades; e os setores públicos e privados envolvidos diretamente na atividade turística.

Como recomendação para trabalhos futuros estão $1^{\circ}$ ) a construção de uma arquitetura para um sistema de inteligência turística com base no Decreto no 8.638 de 15 de janeiro de 2016 e modelo de plataforma eGov voltada ao turismo, e $2^{\circ}$ ) modelagem para a criação do conhecimento organizacional.

\section{REFERÊNCIAS}

AENOR. Ciudades Inteligentes: Datos Abiertos (Open Data). UNE 178301, enero/julio de 2015. Madrid: AENOR, 2015a.

Ciudades Inteligentes: Gestión de los activos de la ciudad. Especificaciones. UNE 178303, mayo de 2015. Madrid: AENOR, 2015b.

AENOR. Sistemas de gestión de los destinos turísticos inteligentes. Requisitos. UNE 178501, abril de 2016. Madrid: AENOR, 2016.

ANDRADE, M. M. Pesquisa Científica: noções introdutórias. In: Introdução à metodologia do trabalho científico: elaboração de trabalhos na graduação. 6 ed. São Paulo: Atlas, 2003.

BILBAO, S.; LEJARAZU, A.; HERRERO, J. Dynamic Packagin Semantic Platform For Tourism. Ulrike Gretzel, Rob Law, Matthias Fuchs (eds). Information and Communication Technologies in Tourism 2010. Proceedings of International Conference in Lugano, Switzerland, February 10-12, Springer International: Wien, 2010.

BIZ, A. A. Plataforma de Negócios em Turismo para Foz do Iguaçu. Universidade Federal do Paraná: Curitiba, 2014.

BRASIL. Decreto $n^{\circ} 8.638$ de 15 de janeiro de 2016. Institui a Política de Governança Digital no âmbito dos órgãos e das entidades da administração pública federal direta, autárquica e fundacional. Diário Oficial, Brasília, n.11, p. 2-3, 18 jan., 2016. Seção 1. PT. 2016a.

BRASIL. Plano de Dados Abertos. Ministério do Turismo, julho de 2016. Disponível em: < http:// dados.turismo.gov.br/images/pdf/PlanodeDadosAbertosparaoMTvs-6.pdf>. Acesso em: 04 de agosto de 2016. $2016 b$.

EUROPEAN COMMISSION. European eGovernment Action Plan 2016-2020. 2016. Disponível em: http:// www.curitibacvb.com.br. Acesso em: 03 de abril de 2017.

GAWER, A. Towards a General Theory of Technological Platforms. Opening Up Innovation: Strategy, Organization and Technology. Imperial College London Business School, June 16 - 18, 2010. Disponível em: < http://www2.druid.dk/conferences/viewpaper.php?id=501981\&cf=43>. Acesso em: 03 de abril de 2017.

. What Managers Need to Know about Platforms. The European Business Review. 2011. Disponível em: < https://spiral.imperial.ac.uk/bitstream/10044/1/13802/2/Gawer\%20article\%20What\%20Managers 
\%20Need\%20to\%20Know\%20about\%20Platforms\%20European\%20Business\%20Review\%202011.pdf>. Acesso em: 04 de abril de 2017.

KALBASKA, N.; JANOWSKI, T.; ESTEVEZ, E.; CANTONI, L. E-Government Relationships Framework in the Tourism Domain. A First Map. Alessandro Inversini, Roland Schegg (eds). Information and Communication Technologies in Tourism 2016: Proceedings of the International Conference in Bilbao, Spain, February 2-5, 2016, p. 73-86.

LARSSON, H.; GRÖNLUND, Å. Future-oriented eGovernance: The sustainability concept in eGov research, and ways forward. Government Information Quarterly, 31, p. 137-149, 2014.

MATTAR, F. N. Pesquisa de Marketing: edição compacta. São Paulo: Atlas, 1996.

MICHOPOUlOU, E.; BUHALIS, D. Developing an eTourism Platform for Accessible Tourism in Europe: technical challenges. Martin Hitz, Marianna Sigala, Jamie Murphy (eds.) Information and Communication Technologies in Tourism 2006: Proceedings of the International Conference in Lausanne, Switzerland, 2006. Springer-Verlag Wien, 2006.

MORENO, M. del C. C.; HÖRHAGER, G.; SCHUSTER, R.; WERTHNER, H. Strategic e-Tourism Alternatives for Destinations. Lis Tussyadiah e Alessandro Inversini (eds). Information and Communication Technologies in Tourism 2015. Proceedings of the International Conference in Lugano, Switzerland, February 3-6, 2015. Springer International Publishing Switzerland 2015.

MOUTET, G. Sharing Regional eGov Platforms: A New Model of Governance. European Journal of ePractice, 18, october/2012, 38-48. Disponível em:< https://ofti.org/wp-content/uploads/2012/10/plateformes.pdf >. Acesso em: 14 de maio de 2017.

OECD. The e-government imperative: Main findings. OECD Observer, Policy Brief. 2003. Disponível em :http:// unpan1.un.org/intradoc/groups/public/documents/APCITY/UNPAN015120.pdf. Acesso em: 12 de abril de 2017.

THE ORGANISATION FOR ECONOMIC CO-OPERATION AND DEVELOPMENT (OECD) ANNUAL REPORT. 2005. Disponível em: https://www.oecd.org/about/34711139.pdf. Acesso em: 08 set. 2017.

PACHECO, R. C. dos S.; SELL, D.; SALM JÚNIOR, J.; TODESCO, J. L. De e-Gov a eGovernança: um novo modelo e-Gov voltado à governança pública. RIGOLIN, Camila Carneiro Dias; BARBORA, Henrianne; HAYSHI, Maria Cristina Piumbato Innocentini (orgs). In: Governo eletrônico, transparência e participação pública no Brasil: reflexões e relatos de experiência. Campinas: Alínea. 2015. Disponível em:https://www.researchgate.net/publication/299584806_De_eGov_a_e-Governanca_Modelo_de_e-gov_voltado_a_governanca_publica. Acesso em: 13 de abril de 2017.

PACHECO, R. C. S. Coprodução em Ciência, Tecnologia e Inovação: fundamentos e visões. In: Joana Maria Pedro e Patricia de Sá Freire. (Org.). Interdisciplinaridade - Universidade e Inovação Social e Tecnológica. 1ed.Curitiba: CRV, 2016, v. 1, p. 21-62.

PAVAN, C. de S. Análise do Fluxo de Informação e Processo de Criação de Conhecimento de uma Destination Management Organization: Estudo de Caso no Curitiba, Região e Litoral Convention \& Visitors Bureau (CCVB). Dissertação de M. Sc., PPGTUR/UFPR. Curitiba, 2016

RANA, Nripendra P.; DWIVEDI, Yogesh K.;WILLIAMS, Michael D. Analysing challenges, barriers and CSF of egov adoption. Transforming Government: People, Process and Policy, v.7, n.2, p. 177 - 198, 2013. Disponível em: http://dx.doi.org/10.1108/17506161311325350. Acesso em: 10 de maio de 2016.

SALM JUNIOR, J. F. (2012). Padrão de Projeto de Ontologias para inclusão de referências do Novo Serviço Público em Plataformas de Governo Aberto. Tese, PPGEGC/UFSC. Florianópolis. Disponível em: $<$ http:// repositorio.ufsc.br/xmlui/handle/123456789/100864>. Acesso em: 16 de julho de 2016.

RAMPELOTTO, A.; LÖBLER, M. L; VISENTINI, M. S. Avaliação do sítio da Receita Federal do Brasil como medida da efetividade do governo eletrônico para o cidadão. Rev. Adm. Pública, v. 49, nº 4, p. 959-983, jul./ ago., 2015. Disponível em: http://dx.doi.org/10.1590/0034-7612131581>.. Acesso em: 01 de agosto de 2016. 
RONCONI, L. Governança pública: um desafio à democracia. Emancipação, Ponta Grossa, 11, (1), 21-34, 2011. Disponível em: < http://www.plataformademocratica.org/Publicacoes/19284.pdf >. Acesso em: 02 de junho de 2016.

TAMBOURIS, E.; KALIVA, E.; LIAROS, M.; TARABANIS, K. A reference requirements set for public service provision enterprise architectures. Softw Syst Model, 13 (3), 991-1013, 2014. Disponível em: $<$ http:// link.springer.com/article/10.1007\%2Fs10270-012-0303-7>. Acesso em: 10 de junho de 2016.

THOMAS, L. D. W.; AUTIO, E.; GANN, D. M. Architectural Leverage: Putting Platforms in Context. The Academy of Management Perspectives, v.28, n.2, p.198-219, 2014. Disponível em:< http:// dx.doi.org/10.5465/amp.2011.0105>. Acesso em: 10 de junho de 2016.

TODESCO, J. L. et al. Ações de gestão do conhecimento para o aprimoramento da política nacional de turismo: arcabouço e diretrizes (Apêndice A). Fevereiro 2014. Projeto de P\&D realizado pelo Programa de PósGraduação em Engenharia e Gestão do Conhecimento. Florianópolis: UFSC, 2014.

UNITED NATIONS. Public Governance Indicators: A Literature Review. New York: Deparment of Economic and Social Affairs. 2007. Disponível em: http://unpan1.un.org/intradoc/groups/public/documents/un/ unpan027075.pdf>. . Acesso em: 01 mai. 2016.

UNITED NATIONS. United Nations E-Government Survey 2014: E-Government For The Future We Want. 2014. Disponível em: https://publicadministration.un.org/egovkb/portals/egovkb/documents/ un/2014-survey/e-gov_complete_survey-2014.pdf. Acesso em: 01 maio 2016.

WIMMER, M. A. A European perspective towards online one-stop government: the eGOV Project. Electronic Commerce Research and Applications, 1, 92-103, 2002. Disponível em < http://ac.els-cdn.com.ez22.periodicos.capes.gov.br/S156742230200008X/1-s2.0-S156742230200008Xmain.pdf?_tid=ab09d798-3635-11e6-

b2cc-00000aab0f01\&acdnat=1466351661_3241664bf747caea4e4979909d355a6a>. Acesso em: 23 de março de 2016.

WORLD BANK. What is Governance?. 2013. Disponível em: http://info.worldbank.org/governance/wgi/ index.aspx\#home. Acesso em: 14 de abril de 2015.

WORLD ECONOMIC FORUM. The Travel \& Tourism Competitiveness Report 2017: Paving the way for a more sustainable and inclusive future. 2017. Disponível em: http://www3.weforum.org/docs/ WEF_TTCR_2017_web_0401.pdf. Acesso em: 15 de julho de 2017.

WORLD TRAVEL \& TOURISM COUNCIL. Travel \& Tourism Economic Impact 2018 Brazil. Disponível em: https://www.wttc.org/-/media/files/reports/economic-impact-research/countries-2018/brazil2018.pdf. Acesso em: 10 de maio de 2018.

\section{Notas}

[1] PRONATEC é o Programa Nacional de Acesso ao Estudo Técnico e Emprego, de gestão do Governo Federal. Disponível em: http://pronatec.mec.gov.br

[2] CCVB - Disponível: http://www.curitibacvb.com.br 